MIDPI

sciforum
MOL2NET, International Conference Series on Multidisciplinary

Sciences

USINEWS-04: US-IN-EU Worldwide Science Workshop Series, UMN, Duluth, USA, 2020

\title{
Synthesis, characterization of Okra mucilage as a potential new age therapeutic intervention
}

\author{
Kunal Pal ${ }^{a, b^{*}}$
}

${ }^{a}$ Department of Life Science and Biotechnology, Jadavpur University, Kolkata-700032, India.

${ }^{b}$ Division of Molecular Medicine and Centre for Translational Research, Bose Institute, Kolkata-700056, India.

*Corresponding author email: kunalpal685@gmail.com

Graphical Abstract
The application of natural polysaccharides in
novel drug delivery systems to deliver the
bioactive agents has been hampered by the
synthetic polymers. The main benefits of the
natural polysaccharides are their biodegradable,
biocompatible, non-toxic, abundant and
economic. Because of the advances in drug
delivery technology, natural polysaccharides are
included in novel drug delivery to fulfill
multitask functions and in some cases directly or
indirectly control the extent and/or rate of drug
release. Substantial research efforts have been


directed towards developing safe and efficient natural based polysaccharide particulate drug delivery systems. The present work outlines the natural based okra mucilage and their isolation, purification, standardization and characterization along with their biological applications are covered.

Keywords: Natural Polysaccharides; Okra mucilage; Standardization; Characterization; Application

\section{Introduction}

Natural polymers are generally obtained from plant and animal kingdom. Most of the natural polymers are high molecular weight; water soluble polymers made up of monosaccharide units and joined by glycosides linkage [1]. Gummy exudates of natural polymers such as protein, enzyme, muscle, fiber, and polysaccharide have been used to formulate various pharmaceutical products $[1,2]$. The well-known natural polymers are gelatin, aloe mucilage, guar gum, karaya gum, bhara gum, sodium alginate, locust bean gum, okra gum and linseed mucilage. These natural polymers are applicable in different pharmaceutical dosage forms like matrix controlled systems, microspheres, nanoparticles, buccal films and viscous liquid formulations $[3,4]$. The specific application of natural polysaccharides in pharmaceutical preparation is to help in the processing of drug delivery systems during its manufacturing, protection, enhancement of stability, bioavailability and patient acceptability [5,7]. Gums have various pharmaceutical applications such as suspending agent for insoluble solid component in mixture, emulsifying agent for resin oils and adhesive in troche masses and pills [8]. Okra is an erect annual plant, botanically known as Abelmoschus esculentus (Family: Malvaceae). Polysaccharide composed 
of D-galactose, L-rhamnose and L-galacturonic acid. Okra is recognized for its gelatinous mucilage solution that results when it is compressed and extracted in water [9]. Okra gum has been used as a pharmaceutical excipient i.e. binder, control release, film coating, bio-adhesive and suspending agent [10]. Okra gum has been evaluated as a controlled release agent in customized release matrices, in contrast with sodium carboxy methyl cellulose (NaCMC) and hydroxyl-propyl-methylcellulose (HPMC), with drug [11]. Okra gum matrices provide a controlled-release of drug for more than $6 \mathrm{~h}$ and the release rate followed time-independent kinetics [12]. The result indicates that Okra gum matrices were useful in the formulation of sustained-release tablets for up to $6 \mathrm{~h}$. In addition, immature fruit have long been applied to relieve pain, moisturize skin, induce sweating, prevent scurvy and treat urinary disorders. Okra mucilage has also been used as a plasma replacement and blood volume expander. The okra mucilage is a polysaccharide composed of galacturonic acid, rhamnose and glucose since it shows hypoglycemic activities. Medicinally in treatment of several disorders, Anti-cancer, antimicrobial, anti-ulcer activity of fresh fruits is recently reported [13,15]. Natural polymers such as chitosan, gelatin, polylactic acids, okra mucilage and their derivatives have been widely studied for their ability to form microspheres [16,17]. These polymer-based materials are oriented to prepare microspheres and nanoparticles. So far, various studies have been reported on the development of these carriers which have been used in the preparation of microspheres. The most famous applications of microspheres are wastewater treatment, immobilization of enzymes and the preparated alginate, polystyrene, polyacrylamide, polyvinyl alcohol, nitrocellulose, etc. Recently, dosage forms that can easily and accuratly control release rate and target the drug to specific site have made great influence for the formulation and improvement of novel drug delivery systems. Microspheres have given a significant role in novel drug delivery systems [18]. Multi-particulate drug delivery systems are mainly oral dosage forms which consist of multiplicity of small discrete units, each exhibit some desired characteristics. To deliver the recommended total dose, these subunits are filled in sachet, encapsulated and compressed into a tablet. For the development of multi-particulate dosage forms in preference to single unit systems because of their benefits such as increased bioavailability, reduced risk of systemic toxicity, reduced risk of local irritation and predictable gastric emptying [19,20]. Losartan potassium, a 
non-peptide molecule, losartan is a competitive antagonist and inverse agonist of angiotensin II receptor (A-II). It is thousands times more selective for AT1 than AT2 receptor. It does not block any other receptor or ion channel, except thromboxane A2 receptor. It blocks all actions of A-II like vasoconstriction, central and peripheral sympathetic stimulation, release of aldosterone and adrenaline from adrenals, renal actions promoting salts and water reabsorption, central actions like thirst, vasopressin release and growth-promoting actions on heart and blood vessels [21].
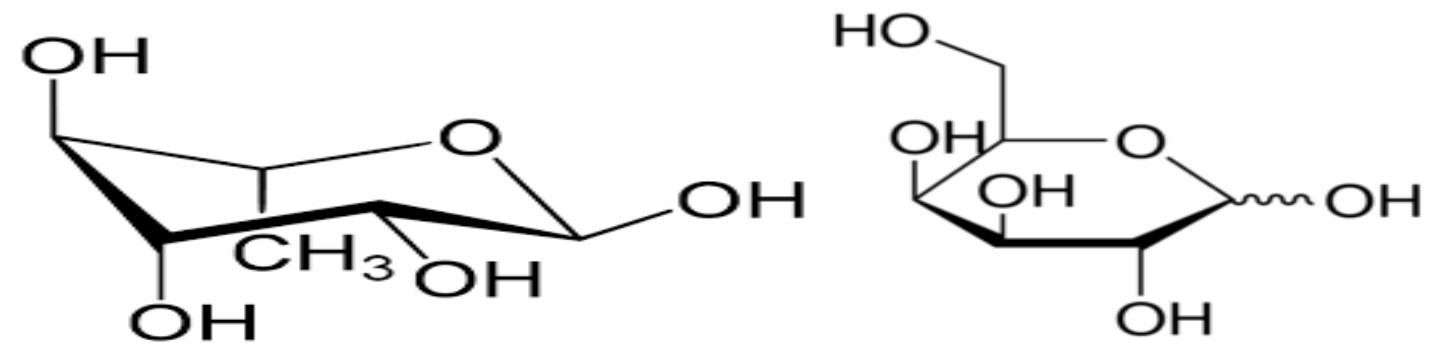

Fig.1. Structure of L-Rhamnose and D-Galactose

\section{Materials and Methods}

\section{MATERIALS:}

\section{Chemical:}

1. Absolute Ethanol

2. Distilled water

3. Fresh Okra fruits-Collected from local market.

4. Luria Broth (LB) medium

\section{Bacterial Strain:}

1. Escherichia coli-collected from department of Bio-Technology, JU.

2. Bacillus subtilis-collected from department of Bio-Technology. 


\section{EXTRACTION OF NATURAL POLYMER FROM OKRA FRUIT}

Okra (Abelmoschus esculentus) was collected from local market of Jadavpur, Kolkata. Authentication of plant material has been done by Prof. Parimal Karmakar, Department of life Sc. And Biotechnology, Jadavpur University. Collected okra (Abelmoschus esculentus) was carefully washed with distilled water. Cut into small pieces placed in a $1000 \mathrm{ml}$ beaker.

Extraction of mucilage: As described elsewhere, powdered fruit was put in 1000ml beaker containing $500 \mathrm{ml}$ of distilled water, then heated and stirred continuously at $60^{\circ} \mathrm{C}$ for approximately 6 hours. Concentrated solution was filtered through muslin cloth and cooled at $4{ }^{\circ} \mathrm{C}-6^{\circ} \mathrm{C}[22]$.

Isolation of Mucilage: As described previously [22], extracted gum has isolated in absolute ethyl alcohol. This allows filtration through muslin cloth. Washed with ethyl alcohol and the mucilage filtrated through muslin cloth. Pressed mucilage was further dried to constant weight at $35-45^{\circ} \mathrm{C}$ in hot air oven. Hard mucilage cake was grinded and stored in desiccator for further used [23].

\section{DESCRIPTION OF CHARACTERIZATION METHODS}

For characterization of the mucilage nanoparticles following methods were necessary by means of which we can confirm the production of natural polymer (mucilage nanoparticles); we can have an idea of its size distribution profile and the average particle size as well. The following experiment were carried out to characterize the mucilage nanoparticles that we synthesized biologically.

Determination of Carbohydrates in Okra Mucilage: Aqueous extract was mixed with Molish's reagent followed by addition of sulphuric acid. The violet colour ring appeared at junction, showing presence of carbohydrates [24].

Determination of purity of okra mucilage: To measure the purity of extracted mucilage, tests for alkaloids, proteins, gum, fats, tannins and amino acids were performed [25].

Ash Values: As discussed by authors in previous publication ash values such as total ash, acid insoluble ash and water- soluble ash were determined using equation 1, 2, 3 respectively [15].

$$
\begin{gathered}
\text { Total ash value }=\frac{\text { weight of ash }}{\text { weight of polymer }} \times 100 \\
\text { Acid insoluble ass }=\frac{\text { weight acid insoluble ash }}{\text { weight of dried powder }} \times 100 \\
\text { Water soluble ass }=\frac{\text { weight of } \text { water soluble ash }}{\text { weight of dried powder }} \times 100
\end{gathered}
$$

Solubility Behavior: One part of dry mucilage powder was shaken with different solvents and further solubility was determined [13]. It is actually soluble in non-polar solvent mostly soluble in water and insoluble in polarsolvent. From this experiment we can know that whether it is polar or nonpolar. 
pH of Mucilage: The mucilage was weighed and dissolved in water separately to get a $1 \% \mathrm{w} / \mathrm{v}$ solution. The $\mathrm{pH}$ of solution was determined using digital $\mathrm{pH}$ meter as described by authors in previous publication [13]. The $\mathrm{pH}$ of okra mucilage is around 7.5 which means it is not acidic not basic in nature i.e. neutral.

UV-Vis Spectroscopy: UV-Vis spectroscopy can be comprehended as absorption spectroscopy in the spectral region of ultra-violet and visible spectra. Generally, it uses light in visible and near-UV range. Ultraviolet and visible light are energetic enough to promote outer electrons to higher energy levels, and UV-Vis spectroscopy is usually applied to molecules in solution. The UV-Vis spectra have broad features that are of limited use for sample identification but are very useful for quantitative measurements. The concentration of an analyte in solution can be determined by measuring the absorbance at specific wavelength and applying the Beer-Lambert Law. Since the UV-Vis range spans the range of human visual acuity of approximately $400-750 \mathrm{~nm}, \mathrm{UV}-\mathrm{V}$ is spectroscopy is useful to characterize the absorption, transmission, and reflectivity of a variety of technologically important materials, such as pigments, coatings etc.

The mucilage nanoparticles were dispersed in MilliQ water to form a diluted suspension of $2 \mathrm{mg} / \mathrm{ml}$ using a bath sonicator for 30mins. When particles were completely dispersed in water its absorbance intensity was measured using UV visible spectrophotometer (Bio-Tek). It does not show any sharp peak due to absence of unsaturation part in MNPs.

Dynamic Light Scattering: The dynamic light scattering (DLS) or photon correlation spectroscopy is a method frequently used in the study of material science and geology to obtain the size distribution profile of mucilage nanoparticles present in suspension or solution. Dynamic Light Scattering Analyzer is the instrument required for DLS analysis.

The working principle of DLS states that the particles, emulsions and molecules in suspension undergo Brownian motion. This is the motion induced by the bombardment by solvent molecules that themselves are moving due to their thermal energy.

Average particle diameter and size distribution of biopolymeric NPs were measured by DLS using a Zetasizer(NANO ZS90, Malvern Instruments Ltd,UK). The charge of the NP was also measured by the Zetasizer. The nanoparticles were dispersed in MilliQ water to form diluted suspension of $2 \mathrm{mg} / \mathrm{ml}$ using bath sonicator for $30 \mathrm{~min}$. After being completely dispersed in water the particle was analyzed by DLS in Zetasizer.

Fourier-Transform Infrared Spectroscopy:The chemical composition of the synthesized mucilage nanoparticles was studied by using Perkin-Elmer RXI FT-IR spectrophotometer with the sample prepared as a $\mathrm{KBr}$ pellet. The solutions were dried at $75^{\circ} \mathrm{C}$ and the dried powders were characterized in the range $4000-400 \mathrm{~cm}-1$ using $\mathrm{KBr}$ pellet method. 


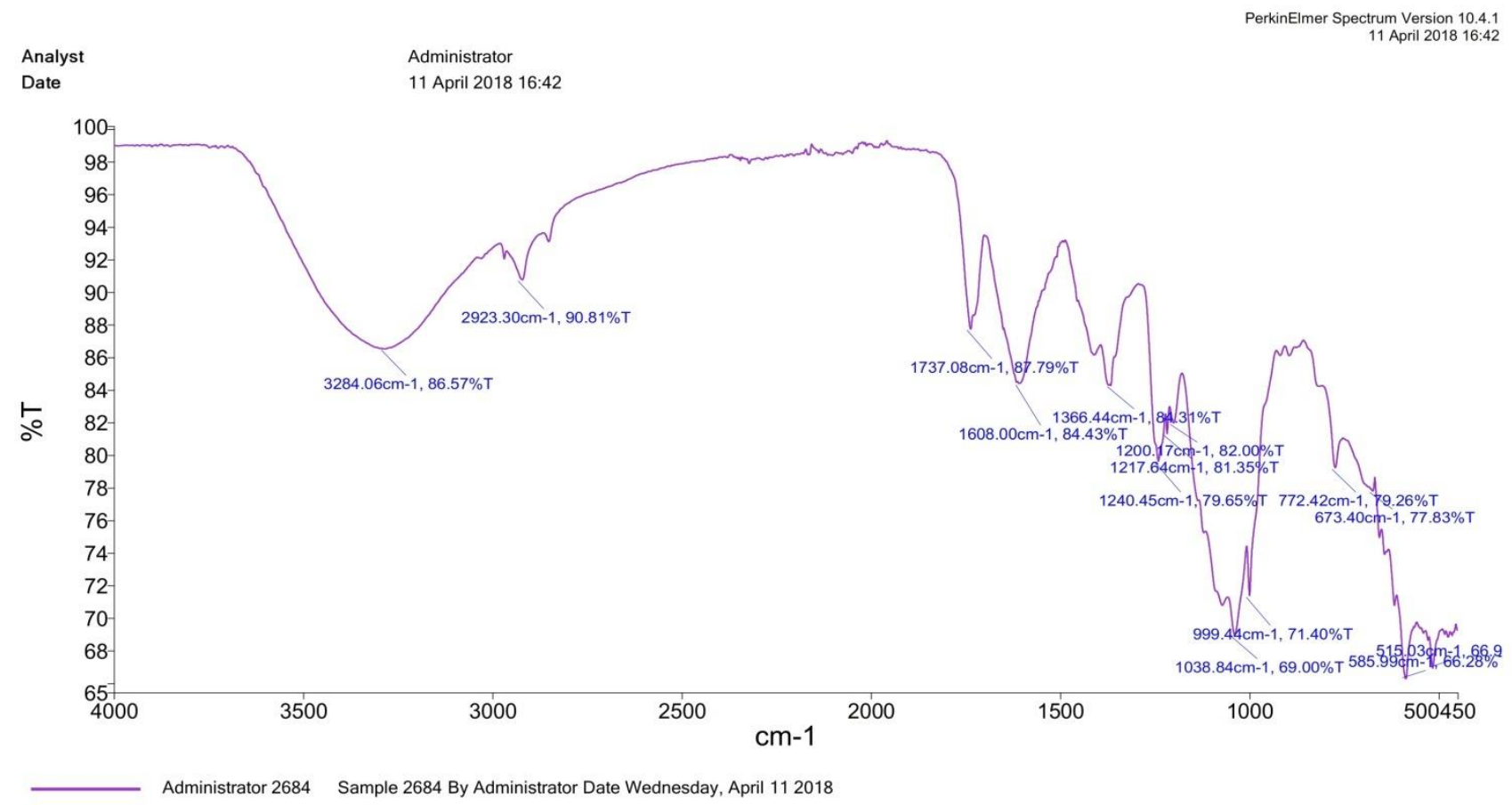

Fig -3: Fourier-Transform Infrared Spectroscopy of Okra Mucilage

\section{ANALYSIS OF MUCILAGE, AMPICILLIN AND AMPICILLIN LOADED MUCILAGE}

Ampicillin Loading in Mucilage: $80 \mathrm{mg}$ mucilage was dissolved in $4 \mathrm{ml}$ distilled water by using magnetic stirrer to dissolve completely up to 6 hours in a small beaker and $20 \mathrm{mg}$ ampicillin was dissolved in $2 \mathrm{ml}$ distilled water simply. Therefore, ampicillin solution was added to beaker drop by drop using micropipette with continuous stirring up to 16 hours to completely loaded the ampicillin in mucilage. Then evaporate the water from this ampicillin loaded mucilage and placed it in a desiccator to remove water completely.

Thereafter, these experimentswere carried out to confirm whether the drug (ampicillin) are loaded or not.

UV-Vis analysis:The absorbance spectrum of mucilage nanoparticle does not show any sharp peak in its spectrum due to its UV inactiveness whereas, mucilage NPs shows a broad absorbance peak centered at $280 \mathrm{~nm}$. In case of the ampicillin loaded NPs there is a significant in the UV spectrum where the absorbance is shifted to $340 \mathrm{~nm}$. The presence of such peaks in the spectrum of Mucilage NPS@AMP confirms the successful incorporation of curcumin in this polymeric structure (Fig. 1b). 


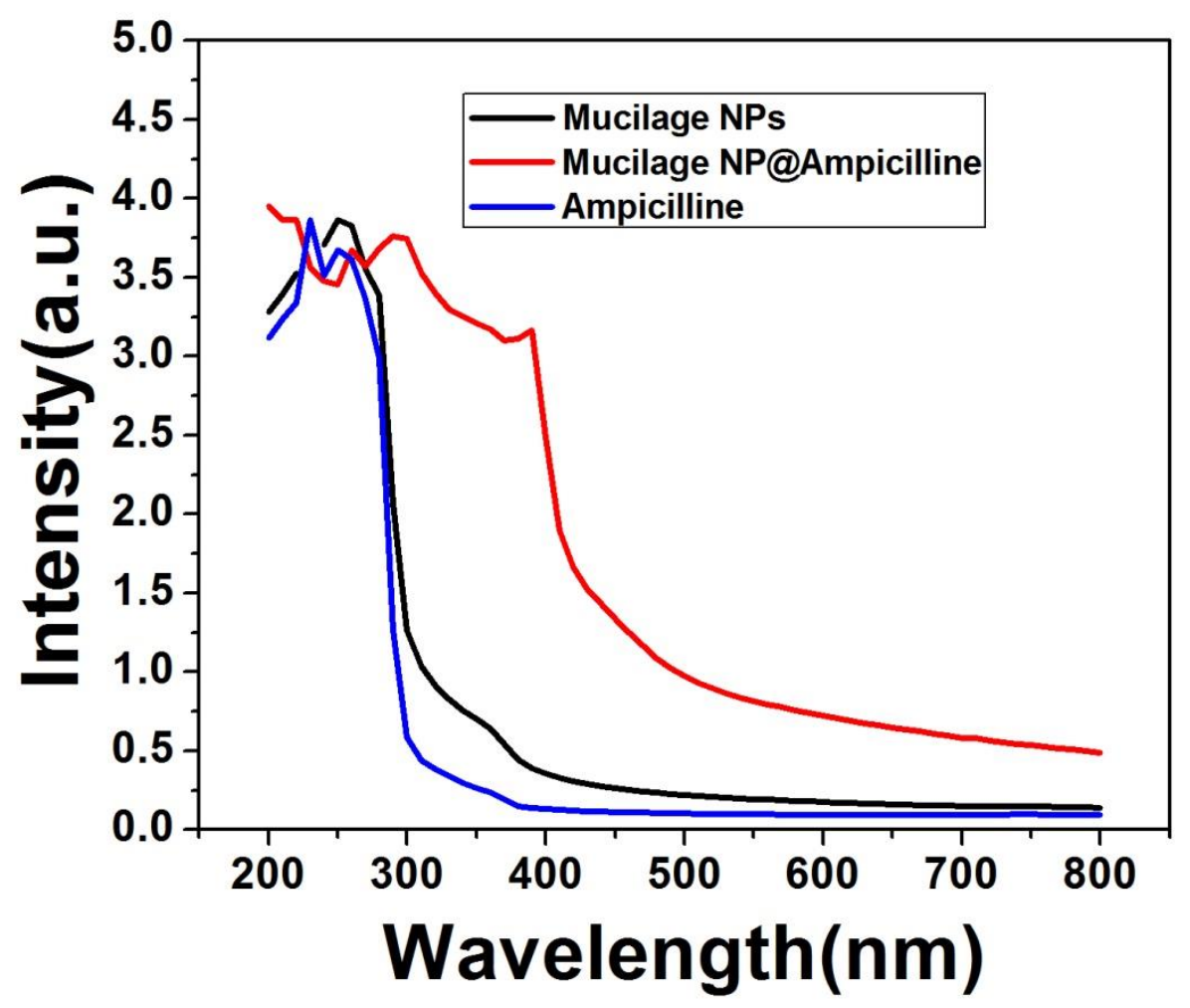

Fig. 4.UV-Vis Spectroscopy Curve

Dynamic Light Scattering and Zeta Potential Analysis:Dynamic light scattering or Photon Correlation Spectroscopy is a technique used in material physics for determining the size distribution profile of silver nanoparticles which were dispersed in deionized water. Light scattering technique is used here to determine the size distribution profile of nanoparticles present in the final solution after ultracentrifugation. The study revealed that the average hydrodynamic particle size of MNPs is 590 d.nm where as in case of MNP@AMP is enhanced to 1290 d.nm which suggests the encapsulation of the antibiotic in the mucilage nanoparticles. The PDI values are 0.451 in case of bare nanoparticles and 0.564 in case of loaded nanoparticle which suggests the homogeneity of the solution. The zeta potential of the bare nanoparticle was found to be $-16.4 \mathrm{mV}$ and in case of ampicillin loaded nanoparticles the zeta potential increased to -19 . 4mV.This also depicts the conjugation of the ampicillin in the nanoparticles. 


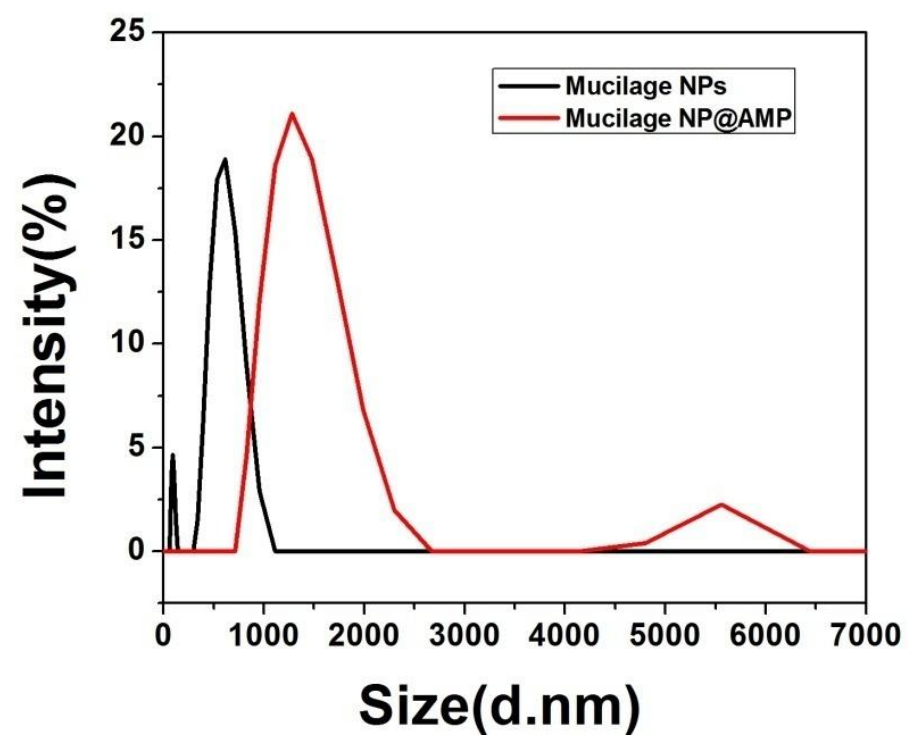

Fig.5.The DLS Curve Shows that the Average Particle Size

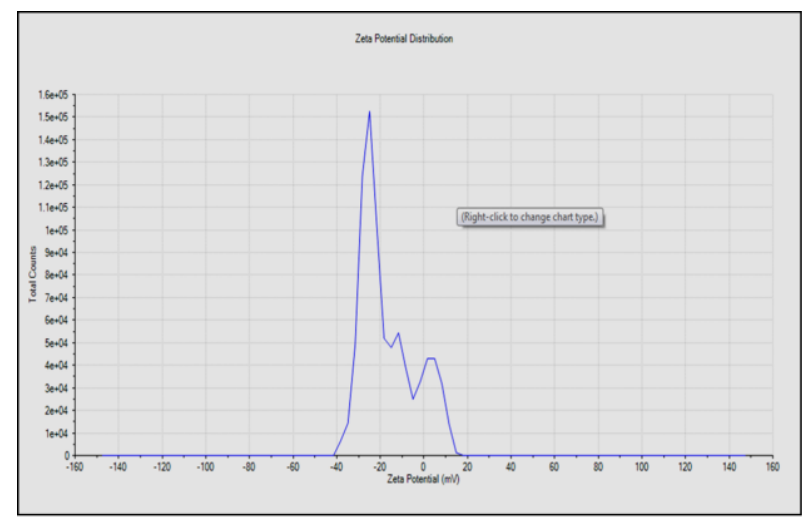

Mucilage NP

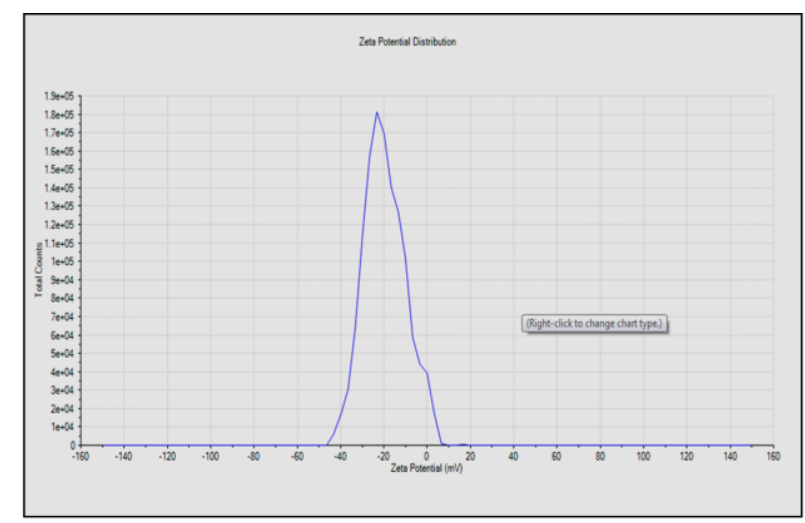

Mucilage NP@Ampicilline

\section{Fig.6. Zeta Potential Curve}

FT-IR analysis:Formation of Mucilage NP@AMP was confirmed by FT-IR study. (Fig. The analysis depicts that the bare mucilage nanoparticles exhibit strong band at $3284 \mathrm{~cm}^{-1}$ (-OH stretching) and $2923 \mathrm{~cm}^{-1}$ (-CH stretching). Vibrational peaks at 1608 and $1366 \mathrm{~cm}^{-1}$ (symmetric and asymmetric stretching of -COO-) indicate the formation of mucilage nanoparticles. Conjugation of ampicillin with mucilage nanoparticle is indicated by a peak at $1510 \mathrm{~cm}^{-1}\left(\mathrm{C}-\mathrm{C}\right.$ stretching) and $1627 \mathrm{~cm}^{-1}(-\mathrm{C}=\mathrm{O}$ vibration). These results confirm the encapsulation of the ampicillin in the mucilage nanoparticles. 


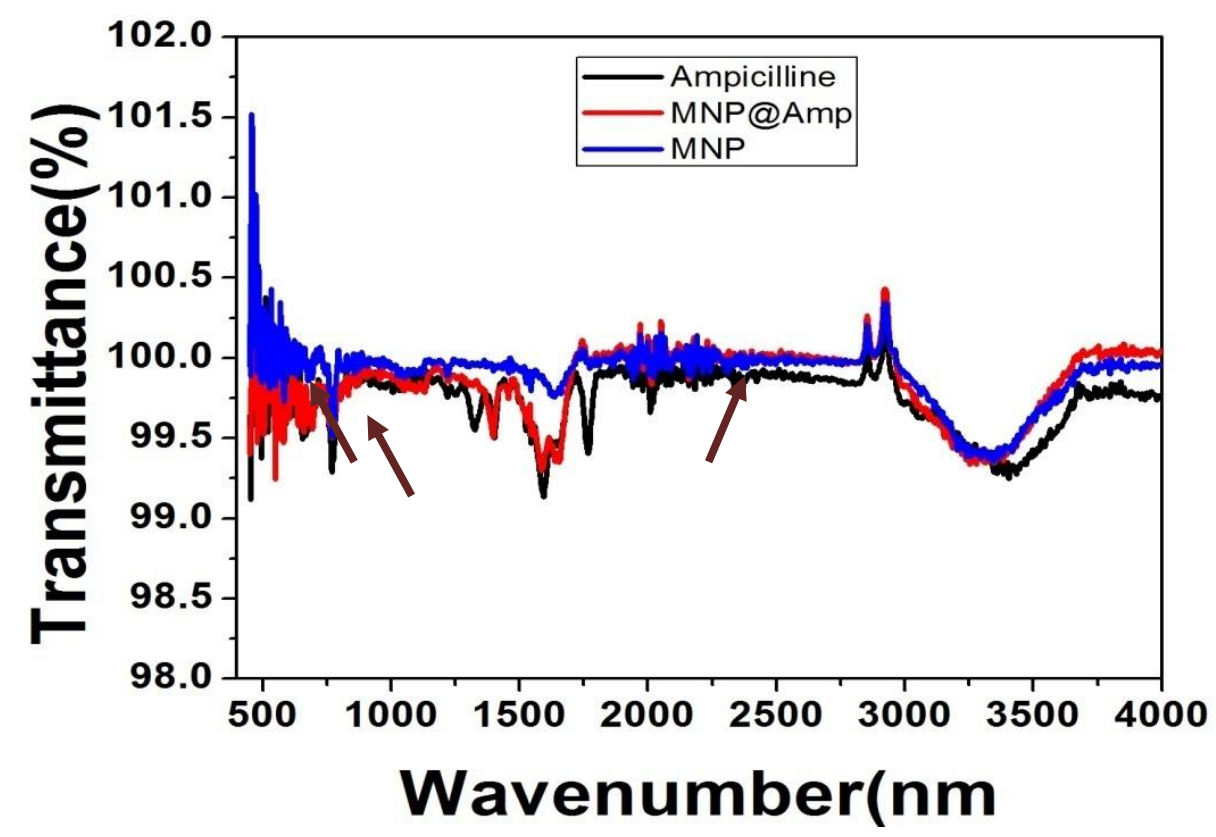

Fig.7.FT-IR of Ampicillin, Mucilage and Ampicillin Loaded Mucilage

\section{RESULTS AND DISCUSSION}

\section{MIC Methods:}

MIC is defined as the lowest concentration of antimicrobial agent that inhibits visible growth of microorganisms in Luria Broth (LB) medium. Test tubes containing $4 \mathrm{ml}$ of broth was inoculated with overnight cultures of the bacteria andthen various concentrations of different minerals $\left(0 \mathrm{mg} \mathrm{ml}^{-1}-0.6\right.$ $\mathrm{mg} \mathrm{ml}^{-1}$ ) for the fractions (S3) were added in each tube. The tubes were left for shaking at $37^{\circ} \mathrm{C}$ for 24 hr. Then optical density of each tube was measured at $600 \mathrm{~nm}$ for the determination of bacterial growth. 


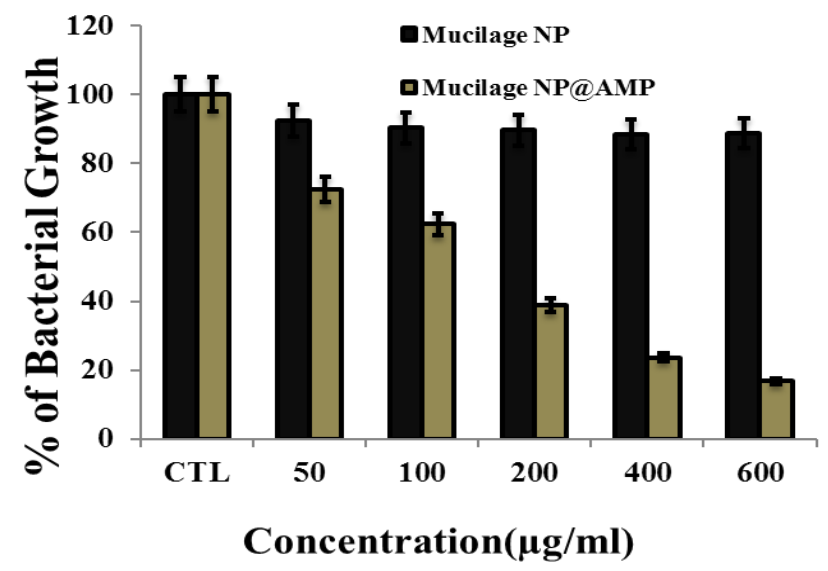

E.coli

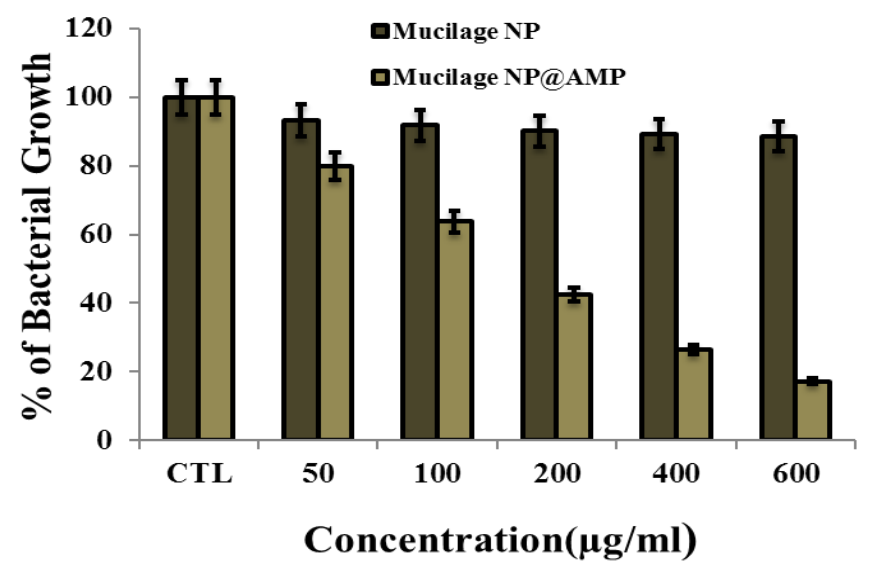

S.aureus

Fig. 8 Inhibition of Bacterial Growth Respect to Different Concentration of Bare Mucilage and Ampicillin Loaded Mucilage

\section{Conclusions}

These mucilage nanoparticle is biodegradable and biocompatible. It has many applications especially in case of the wound healing. In this study we have observed a significant antibacterial activity. This may be due to the enhanced bioavailability or stability of the antibiotic, ampicillin. The greater stability of the antibiotic will be the next objective in our study where the stability of the antibiotic may be looked into by application of different parameters like temperature,UV,etc. This is very important in case of tropical countries like India where storage facility is paltry and the average temperature is quite high. Furthermore, several other hydrophilic and hydrophobic drugs can be evaluated

\section{References}

1. Farooq U, Malviya R, Sharma PK (2014) Advancement in microsphere preparation using natural polymers and recent patents. Recent Pat Drug Deliv Formul 8: 111-125.

2. Farooq U, Malviya R, Sharma PK (2014) Extraction and characterization of artocarpus integer gum as pharmaceutical excipient. Polim Med 44: 69-74.

3. Krishna LNV, Kulkarni PK, Dixit M, Lavanya D, Ravi PK (2011) Brief introduction of natural gums, mucilages and their application in novel drug delivery systems. International Journal of Drug Formulation and Research 2: 52-63.

4. Pawan P, Mayur P, Ashwin S (2001) Role of natural polymer in sustained release drug delivery system. International Research Journal of Pharmacy 2: 6-11. 
5. Malviya R, Srivastava P, Kulkarni GT (2011) Application of mucilage in drug delivery. Advances in Biological Research 5: 1-7.

6. Sujitha B, Krishnamoorthy B, Muthukumaran M (2012) A role of natural polymers used in formulation of pharmaceutical dosage form. International Journal of Pharmacy and Technology 4: 2347-2362.

7. Dharmendra S, Surendra JK, Sujata M, Shweta S (2012) Natural excipients. International Journal of Pharmaceutical and Biological Archives 3: 1029.

8. Girish KJ, Dhiren PS, Prajapatia DV, Jainb VC (2009) Gums and mucilages: versatile excipients for pharmaceutical formulations Gums and mucilages. Asian Journal of Pharmaceutical Sciences 4: 308-309.

9. Ogaji IJ, Nep EI, Audu-Peter JD (2011) Advances in natural polymers as pharmaceutical excipients. Pharmaceutica Analytica Acta 3: 1-16.

10. Ahad HA, Sreenivasulu R, Rani EM, Reddy VB (2011) Preparation and evaluation of famotidine high density gastro retentive microspheres with synthetic and natural polymers. J Pharm Educ Res 2: $110-118$.

11. Morkhade DM, Fulzele SV, Satturwar PM, Joshi SB (2006) Novel matrix forming materials for sustained drug delivery. Indian J Pharm Sci 68: 53-58.

12. Bhardwaj V, Kumar S (2012) Design and characterization of novel interpenetrating polymer network mucoadhesive microspheres of locust bean gum and PVA for controlled release of metformin HCl. Int Pharm Sci 2: 115-121.

13. Devrim B, Canefe K (2006) Preparation and evaluation of modified re- lease ibuprofen microspheres with acrylic polymers (eudragit) by quasi- emulsion solvent diffusion method: Effect of variables. Acta Poloniae Pharm Drug Res 63: 522-523.

14. Tavakoli N, Ghasemi N, Taimouri R, Hamishehkar H (2004) Evaluation of okra gum as a binder in tablet dosage forms. Iranian Journal of Pharmaceutical Research Res 2: 47.

15. Momoh MA, Akikwu MU, Ogbona JI, Nwachi UE (2009) In Vitro Study of Release of Metronidazole Tablets Prepared from Okra Gum, Gelatin Gum and their Admixture. BioResearch 6: 339-342.

16. Kalu VD, Odeniyi MA, Jaiyeoba KT (2007) Matrix properties of a new plant gum in controlled drug delivery. Arch Pharm Res 30: 884-889.

17. Ogaji I, Noli O (2010) Film coating potential of okra gum using paracetamol tablets as a model drug. Asian Journal of Pharmaceutics 4: 130-134.

18. Attama AA, Adikwu MU, Amorha CJ (2003) Release of indomethacin from bioadhesive tablets containing carbopol 941 modified with Abelmuschus esculentus (okra) gum. Boll Chim Farm 142: 298-302. 
19. Amin IM (2011) Nutritional Properties of Abelmoschus Esculentus as Remedy to Manage Diabetes Mellitus: A Literature Review. International Conference on Biomedical Engineering and Technology 11: 1-5.

20. Nasipuri RN, Igwilo CI, Brown SA, Kunle OO (1996) Mucilage from Abelmuschus esculentus (okra) fruits- a potential pharmaceutical raw material; part1; physicochemical properties. Journal of Pharmaceutical Research and Development 1: 22-28.

21. Patel J, Bharadia P, Amin A, Patel M (2004) Formulation optimisation and evaluation of controlled release mucoadhesive microspheres of glipizide for oral delivery using factorial design. Drug Deliv 4: 48-53.

22. Farooq U, Sharma PK, Malviya R (2014) Extraction and Evaluation of Okra Mucilage as Pharmaceutical Excipient. Academic Journal of Plant Sciences 6: 168-172.

23. Ravi Kumar MN (2000) Nano and microparticles as controlled drug delivery devices. J Pharm Pharm Sci 3: 234-258.

24. Delie F, Blanco-Príeto MJ (2005) Polymeric particulates to improve oral bioavailability of peptide drugs. Molecules 10: 65-80.

25. Pamujula S, Graves RA, Kishore V, Mandal TK (2004) Preparation and in vitro characterization of amifostine biodegradable microcapsules. Eur J Pharm Biopharm 57: 213-218 